\title{
The Impact of COVID-19 Pandemic on Children with Disabilities: The Case of Chiredzi South, Zimbabwe
}

\author{
Gumbo Olivia, Gumbo Douglas, Musingafi Maxwell, Nyaruwata Leonorah \\ Department of Development Studies, Zimbabwe Open University, Harare, Zimbabwe \\ Email: oliviagumbo@gmail.com
}

How to cite this paper: Olivia, G., Douglas, G., Maxwell, M., \& Leonorah, N. (2022). The Impact of COVID-19 Pandemic on Children with Disabilities: The Case of Chiredzi South, Zimbabwe. Open Journal of Political Science, 11, 46-62.

https://doi.org/10.4236/ojps.2022.121004

Received: August 20, 2021

Accepted: January 11, 2022

Published: January 14, 2022

Copyright $\odot 2021$ by author(s) and Scientific Research Publishing Inc. This work is licensed under the Creative Commons Attribution International License (CC BY 4.0).

http://creativecommons.org/licenses/by/4.0/

\begin{abstract}
Children with disabilities in Zimbabwe faced several economic, social and cultural challenges due to crumbling economy and socialisation. Their plight further deteriorated with the advent of COVID-19 pandemic that struck the world economy. Zimbabwe was not spared from this as most parents of children with disabilities are in the informal sector that was badly hit by COVID-19 lockdown measures that prohibited them from trading. This affected children with disabilities to access their basic needs. The study was conducted on children with disabilities in Chiredzi South which is a rural community. The study used qualitative methodology in the form of desk review and virtual questionnaires and key informant interviews. These virtual interviews used the ODK application and ONA server. The main findings of the study were that there are eight disabilities types in Chiredzi South that are prevalent to children, lack of movement enablers, lack of telecommunication infrastructure hindered education and health access for children with disabilities. The main conclusions were that children living with disabilities in Chiredzi did not receive meaningful help from government and non-governmental organisations during COVID-19 pandemic; they are further excluded from accessing basic services such as education and health. The recommendations of the study are making sure that special teachers are at schools during lockdown with government providing them with protective equipment, introduction of subsidies to assist children with disabilities in schools, accessibility of appropriate medication for those who live on special medication, and many other recommendations as outlined at the end of the paper.
\end{abstract}

\section{Keywords}

Children with Disabilities, COVID-19, Inclusion, Education, Health 


\section{Introduction}

COVID-19 broke out in Wuhan China in December 2019. The first case in Zimbabwe was reported on 21 March 2020 The first lockdown measures were enforced on 30 March 2020 (Gumbo, 2020). The movement restrictions that were imposed by President E.D. Mngwagagwa commanded every individual to confine to his or her home. People were only allowed to go out of their houses for essential services. Essential services included buying basic necessities at a supermarket or food retail store, or fuel or gas at a fuel or gas retail outlet and buying medicine at the establishment of a pharmaceutical chemist within a radius not exceeding five (5) kilometres from his or her home (Gumbo, 2020). The schools were closed from April 2020. They were opened in a staggered way starting with examinations classes and non-examination classes followed by Grade or Form through November to December 2020. Schools were opened again from March to May 2021 and were closed again from June and were not opened till August. This meant that children were out of school for the greater part of the pandemic and will still continue since the pandemic is still with us for some time. The quarantine centres were not well prepared to deal with persons living with disabilities since most of the centres were former warehouses, schools and colleges that are not disability friendly. Some quarantine centres did not have social welfare officers who could engage with hearing-impaired persons that meant that there was information asymmetry in this group. Cahapay (2020) indicates that "children with disabilities continue to face social exclusion, discrimination and the lack of health services and therapy during quarantine which could lead to lifelong and devastating impact in their development". Newspapers in Zimbabwe reported that at least 5000 girls had fallen pregnant during the pandemic; it remains to be known how many of these were girls living with disabilities as reports are still sketchy. This also affected children with disabilities of school-going age who were meant to be at school. Globally about one billion people with disabilities were impacted by the COVID-19 (Armitage \& Nellums, 2020).

This paper investigates the experiences of pupils with disabilities in the COVID-19 era in Chiredzi South. It starts with an overview of the experiences of children with disabilities in the background as a way of contextualising the study. The paper then presents the purpose, research objectives and research questions of the study, followed by the discussion of related literature and study methodology. Then presentation and discussion of findings drawing conclusions and recommendations from the discussion come.

\subsection{Background on Children Living with Disabilities in Zimbabwe}

Disability has been a concern in the world from time immemorial and it is part of the human condition. It is a complex, dynamic, multidimensional and contested issue (Charlton, 1998). The issue of disability is prevalent in both developed and developing countries, rich and poor families and communities. As 
such, every government world over has faced the moral and political issue of how best to include and support people with disabilities (Mishra \& Gupta, 2006). Bickenbach et al. (1999) posit that disability refers to difficulties encountered in any or all three areas of functioning that are impairments, activity limitations and participation limitations. Impairments are problems in body functions or alterations in body structure such as paralysis or blindness. Activity limitations are difficulties in executing activities such as walking or eating. Participation limitations are problems involved in any area of life, such as facing discrimination in transportation, schooling or employment. On another note, the Zimbabwe Disabled Persons Act, Chapter 17:01 of 1992, defines a disabled person as:

a person with a physical, mental or sensory disability, including a visual, hearing or speech functional disability, which gives rise to physical, cultural or social barriers inhibiting him from participating at an equal level with other members of society in activities, undertakings or fields of employment that are open to other members of society.

In addition, the International Convention on the Rights of People with Disabilities (ICRPD) uses a social model of disability, and sees disability as long-term physical, mental, intellectual or sensory impairments which in interaction with various barriers may hinder the full and effective participation of the affected persons in society on an equal with others. Thus, due to such body restrictions, persons with disabilities are more likely to experience adverse socioeconomic outcomes such as less education, poorer health outcomes, lower levels of employment, and higher poverty rates. This is likely to have more impact on girls with disabilities.

World Bank report of October 2020 postulates that one billion people, or $15 \%$ of the world's population, experience some form of disability, and disability prevalence is higher in developing countries. In Zimbabwe, according to UNICEF (2013) as many as 600,000 children are living with disabilities. Furthermore, many disabled children in Zimbabwe fail to realise their full potential as they struggle to access basic rights, such as education and health (World Bank Report, 2020). In addition, Amlambo, Newsday staff reporter on June 13, 2013 said that the plight of disabled children in Zimbabwe is made worse due to lack of statistics, almost all schools in the country were not wheelchair user friendly and most of the toilets at schools were not compatible with wheelchairs.

Therefore, in addition to the challenges caused by disabilities, the COVID-19 pandemic has worsened the plight of children with disabilities and their families are experiencing particular obstacles in comparison with other families (Kirshner et al., 2010). COVID-19 challenges can negatively influence disabled children's well-being. Although children are less likely than adults to exhibit COVID-19 symptoms, children with disabilities are considered to have more health care needs (UN, 2020), since COVID-19 infection may aggravate existing health conditions, especially those related to respiratory function, immune system function, heart disease, or diabetes (Hartshorn \& McMurry, 2012). The COVID-19 
pandemic is having a disproportionate impact on children with disabilities who were already experiencing social and educational disadvantage. However, the social needs, barriers, and issues for children with disabilities in Zimbabwe urban and rural settings during this COVID crisis have not been well researched.

There is a paucity of information in Zimbabwe, on how disabled children are coping with the COVID-19 pandemic and how they have been affected by the lockdown. Furthermore, the impact of the pandemic on rural children living with disabilities has not been well documented. It has also been observed that the supporting needs of disabled children in this pandemic era have not been established. It is, therefore, the purpose of this paper to analyse the strategies that can be used to help children living with disabilities during COVID-19 period.

\subsection{Purpose}

This paper seeks to analyse the options that can be used to help children living with disabilities during COVID-19 period.

\subsection{Research Objectives}

1) Assess the living conditions of children living with disabilities during COVID-19 era. Understand how the children with disabilities are surviving in their society.

2) Establish the status of the mutual support system for children with disabilities. Identify the support the children with disabilities are getting from their parents, guardians or other stakeholders.

3) Examine the challenges faced by children living with disabilities in rural areas such as Chiredzi South constituency.

4) Identify basic and strategic support needs for children living with disabilities for them to live a quality life.

\subsection{Research Questions}

1) How are children living with disabilities in Chiredzi managing in COVID-19 era?

2) How are children living with disabilities in Chiredzi being helped to cope in the COVID-19 pandemic?

3) What challenges are faced by children living with disabilities in Chiredzi?

4) What are the basic and strategic support needs for children with disabilities in Chiredzi during the COVID-19 period?

\section{Literature Review}

Most governments were not prepared to deal with children with disabilities. There have been disruptions to services, ranging from education to child protection that has been documented, with disproportionate effects on the most vulnerable children and families (UNICEF, 2020a). There is lack of research and data collection to draw attention to the experiences of children with disabilities 
during the pandemic, to advocate for a range of services to be available now and in the future, and to inform the design of specific interventions for children with disabilities (UNICEF, 2020a). About one-quarter of world's countries had social protection system disrupted for persons with disabilities (UNICEF, 2020b). There are prejudices, stigma, and discrimination against people with disabilities, including misconceptions that they cannot contribute to the outbreak response or make their own decisions (UNICEF, 2021).

Children with disabilities are among the world's most disadvantaged groups, they are prone to stigma and discrimination that often lead to increased exposure to abuse, neglect, reduced access to services, and general lack of recognition (UNICEF, 2020b). Furthermore, children with disabilities have greater healthcare needs and dependence on community-based services challenges that were not considered in pandemic response plans (Aishwonya, Ramkuma \& Kany, 2020). The COVID-19 lockdown measures that were enforced by governments led to increased anxiety and depression, and the exacerbation of pre-existing mental health issues for children with disabilities (UNICEF, 2020c).

The lockdown measures led governments to embark on remote homeschooling that was exceptionally difficult to administer special curricula for the rural poor who could not access Internet and related technological resources (Jeste et al., 2020c). The poorest and the most marginalized face an even broader set of risks related to lack of access to social protection services, such as school feeding programmes, information on disease prevention and water and sanitation (UNICEF, 2020b). Limited availability of disaggregated data results in an inability of surveillance systems to determine the impact on people with disabilities. Furthermore, Inaccessible information and communication mean that persons with hearing, visual, intellectual or physical disabilities may not receive key information about prevention and assistance (UNICEF, 2021).

Different countries initiated programmes that empowered children with disabilities with risk communication and community engagement knowledge that helped to improve childcare skills and feeding practices, especially during the pandemic (UNICEF, 2020b). UNICEF Georgia launched a special television broadcast and a Facebook-based platform geared towards helping parents of children with disabilities (UNICEF, 2020c). While other countries like Lebanon and Mongolia launched child-friendly videos on COVID-19 messages that were accessible to children with hearing impairments. In Philippines easy-to-read materials, text captioning, braille, large format print, among others augmented the communication needs of children with disabilities (Cahapay, 2020).

UNICEF Nicaragua provided technical and financial support to strengthen teachers' capacities to work with families who have children with disabilities aged 3 and younger (UNICEF, 2020a). UNICEF recommended the supported caregivers of children with disabilities with their own mental health and psychosocial wellbeing. Most countries in the world offered stimulus packages that supported the continuity of inclusive health and social services used by persons with disabilities, including rehabilitation, assistive technology, and personal assistance 
(UNICEF, 2021). In addition public messaging created respectful and free of bias that avoided the potential for stigma against any part of the population based on age or disability that might lead people to assume that rise in COVID-19 transmission is increased with people with disabilities (UNICEF, 2021). Many protocols would, more or less directly, deprioritize people with chronic disabilities as a group (Dan, 2020).

\section{Methodology}

\subsection{General Description of Study Site}

The research study was conducted in Chiredzi South (Figure 1), part of the Chiredzi District $\left(18^{\circ} 55^{\prime} \mathrm{S}, 29^{\circ} 49^{\prime} \mathrm{E}\right)$ in the south-eastern part of Zimbabwe. Chiredzi South (Matibi 2 and Sengwe Communal area) has nine (9) Wards and stretches from Runde River to the North (Triangle and Hippo Valley Estates) and Limpopo River to the South (borders with Beitbridge District, Republic of South Africa and Southern Mozambique). To the East, it borders Mozambique and includes Gonarezhou National Park, to the West it borders with Mwenezi District. The study area falls in agro-ecological region $\mathrm{V}$ receiving less than 500 mm per annum (Vincent \& Thomas, 1960). The rainfall regimes in Region V are characterised by erratic patterns with frequent mid-season dry spells and early rainfall cut-offs that cause poor crop condition or total crop failure forcing households to rely on livestock and remittances as main source of livelihoods.

One of the main reasons why Chiredzi South was selected was that there is already an active and functional disability chapter that holds events every year in support of people with disabilities.

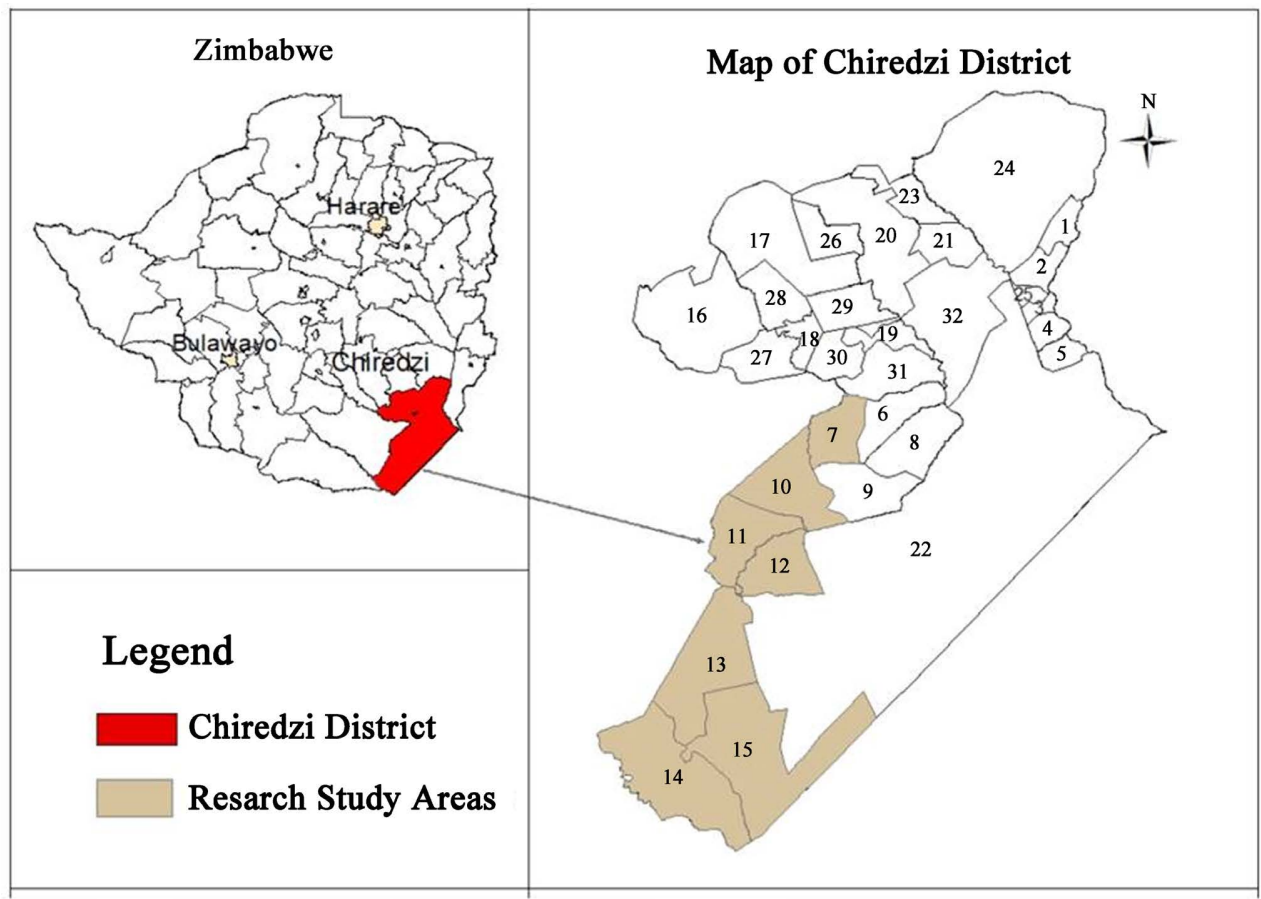

Figure 1. Location of the study area, Wards in Chiredzi South, Chiredzi District, Zimbabwe. 


\subsection{Data Collection}

The Research team reviewed documents on children with disabilities from existing resources more than 100 papers published to gain an understanding of the disability context, trends in the country and as well as gaps to address during fieldwork. This contributed to the design of three (3) types of review instruments (individual questionnaire (Electronic), key informant interviews and level stakeholder consultations (Virtual and face to face) and Focus group discussions. Due to COVID-19 restrictions the team used electronic questionnaires to some participants who had electronic devices and conducted some virtual key informant interviews with those who had access to network. Since the area has network challenges 69 questionnaires were administered to children with disabilities while the district has over 227 children with disabilities.

The quantitative instrument used was an individual questionnaire (survey with closed and open-ended questions) administered by enumerators to children living with disabilities and carers of Children living with disabilities. The data entry template was designed to collect information on relevant indicators using the Open Data Kit (ODK). The enumerators used mobile electronic data collection method to cut down on data entry costs as well as time for capturing data. Electronic forms were downloaded on android devices and completed questionnaires were posted to the Ona Server, a data storage, management and visualisation platform. Data was downloaded, and the Statistical Package for Social Scientists was used for data analysis. Table 1 shows the number of wards and centres where data was collected.

Key informant interviews were done through virtual meetings with Jairos Jiri Coordinator; Parents group Chairpersons, Traditional leaders, Religious leaders and Social Welfare Officer in Chiredzi District. Face to face KII were done with senior traditional leader, Committee member for disability committee, Sister in Charge at health centre and Head teacher/Teacher responsible for children with special needs. Focus group discussions were done with persons living with disabilities and carers for Children living with disabilities.

\section{Findings and Results}

The major findings of the programme revealed that there are eight types of disabilities in Chiredzi South. These are deaf, blind, learning, mental, physical,

Table 1. Wards and Centres where data was collected.

\begin{tabular}{ccccc}
\hline Ward & $\begin{array}{c}\text { No. of } \\
\text { Centres }\end{array}$ & $\begin{array}{c}\text { No. of } \\
\text { Questionnaires }\end{array}$ & $\begin{array}{c}\text { No. of } \\
\text { Enumerators }\end{array}$ & $\begin{array}{c}\text { Each Enumerator } \\
\text { administered }\end{array}$ \\
\hline 10 & 3 & 38 & 3 & 38 \\
11 & 1 & 13 & 1 & 13 \\
12 & 1 & 9 & 1 & 9 \\
13 & 1 & 9 & 1 & 9 \\
Total & & 69 & 6 & 69 \\
\hline
\end{tabular}


albinism, speech and multiple. Covid19 had several effects on children living with disabilities including lack of access to basic needs such as education, health and food. Children with disabilities did not get access to basic services during COVID-19 era; they did not get education services, had limited health services, did and felt lonely as they could not interact with their peers. Children with disabilities also did not receive much support from the government and non-governmental organisations, those who did not have movement aids before the pandemic failed to get support during the pandemic and they did not get social services packages or allowances from the government as well.

\subsection{Types of Disabilities}

The study was conducted on 69 children with disabilities. Thirty-nine were girls and thirty were boys. The interviews revealed that there are 8 types of disabilities in Chiredzi South. The types of disabilities are deaf, blind, learning, mental, physical, albinism, speech and multiple as illustrated in Figure 2. The most prevalent disability is physically followed by learning, mental and multiple.

Six children were at ECD level and these were not doing any lessons since the government radio lessons did not cover their level. Thirty-eight were at primary school level, six were attending early childhood development while seven students were at the secondary school level (Figure 3). The number of children who

What is the disability type of the child?

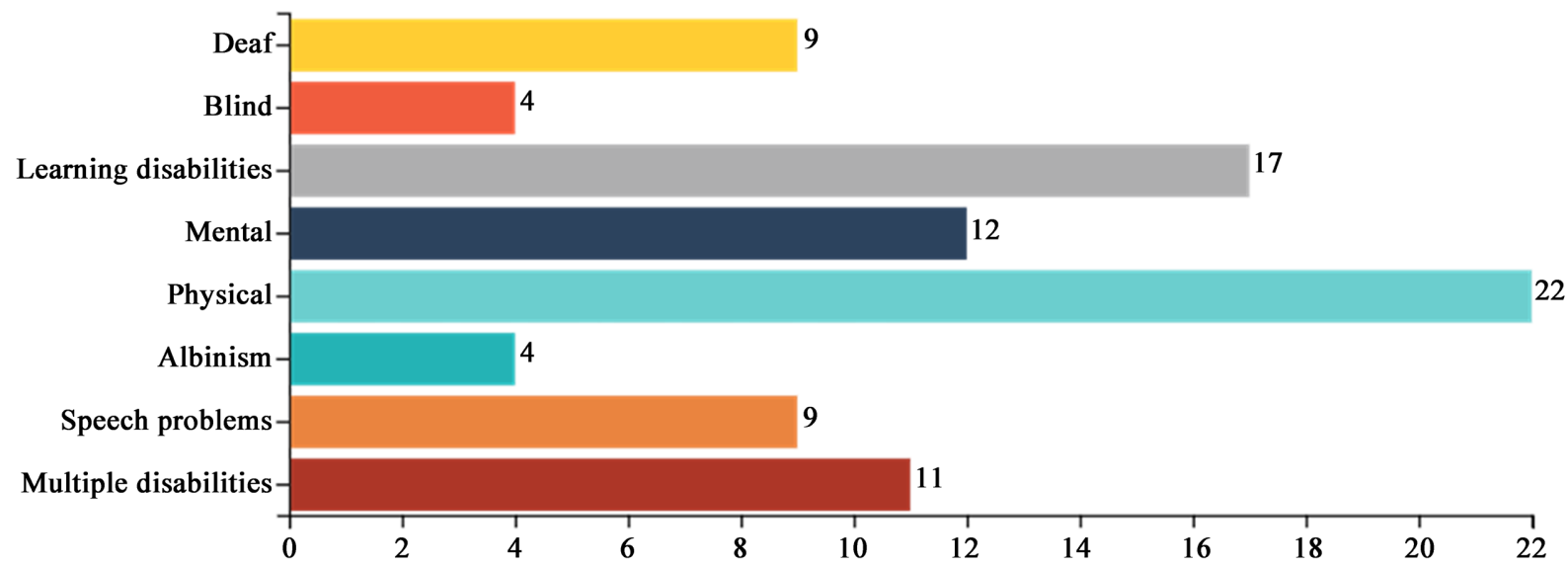

Figure 2. Disability types.

\section{School level of the child}

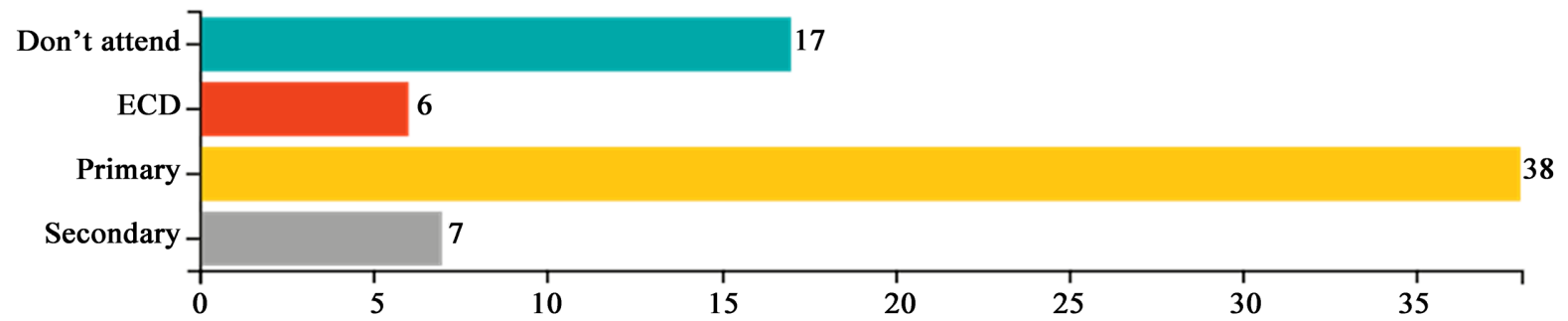

Figure 3. Levels of education in the district for children with disabilities. 
were mostly affected by the pandemic were at the primary level who failed to get access to radio lessons that were being conducted on national radio. It is also alarming to learn that only seven students were at the secondary school level. Seventeen students did not attend school which is $24 \%$ of the students who do not attend school were supposed to be a secondary level but their parents cannot afford secondary level school fees. This shows that children with disabilities are left behind in education and this translates to negative effects on their standard of living, access to livelihoods, confidence level and literacy rate. There were also reports that those who finish secondary level, do not proceed to advanced level or vocational centres because of limited funding from their poor parents and very few donors are focusing on paying school fees for children with disabilities. While there are no government policies that allow children with disabilities to access free education services from primary to tertiary level.

\subsection{Knowledge and Living Conditions under COVID-19 Situation}

Fortunately, most children with disabilities knew there was COVID-19 because they were homebound (Figure 4). However, they were not aware of World Health Organisation's prevention measures that were supposed to be adhered to including social distancing, washing hands with running water and masking up. Community meetings where COVID-19 prevention measures were publicised were normally attended by adults, not children. Children usually get such teachings at schools that were closed. Lack of information about the prevention measures to children with disabilities shows that the government is not prioritising these children in its planning, which is a worrisome development. Alternative ways of disseminating this information are necessary and there should be consideration of the use of braile and sign language for the children who are blind and deaf to understand the information.

\subsection{Major Challenges Faced by Children with Disabilities during COVID-19}

Figure 5 shows the summary of challenges that were faced by children with disabilities during the COVID-19 pandemic period.

Most children highlighted education services as the major challenge they face. These include no access to radio or online lessons, no stationery and non-availability of special teachers. Chiredzi South is a unique ward where local airwaves and transmission are either inaccessible or where there is accessibility it is very poor. Strong signals in the area are either from South Africa or Mozambique. Therefore, radio and online lessons were not ideal for the area. Out of the 69 students who were sampled only 18 students indicated that they were doing radio lessons that were led by the Ministry of Primary and Secondary Education (MoPSE) while 51 were not able to attend the lessons. The primary school students who were supposed to have access to public radio lessons acknowledged that they failed to do so and they will not catch up with other students from other areas who had access to airwaves. Online lessons were mostly conducted by private 


\section{Do you know about COVID?}

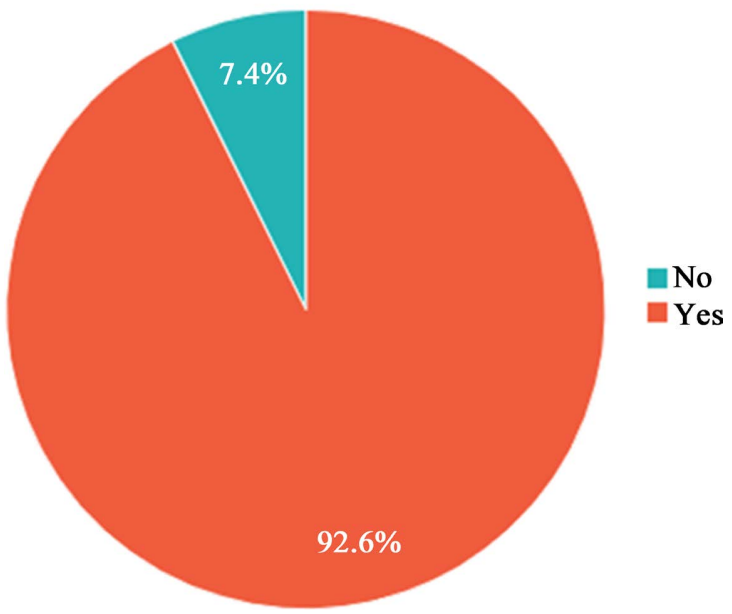

Figure 4. Knowledge of COVID-19.

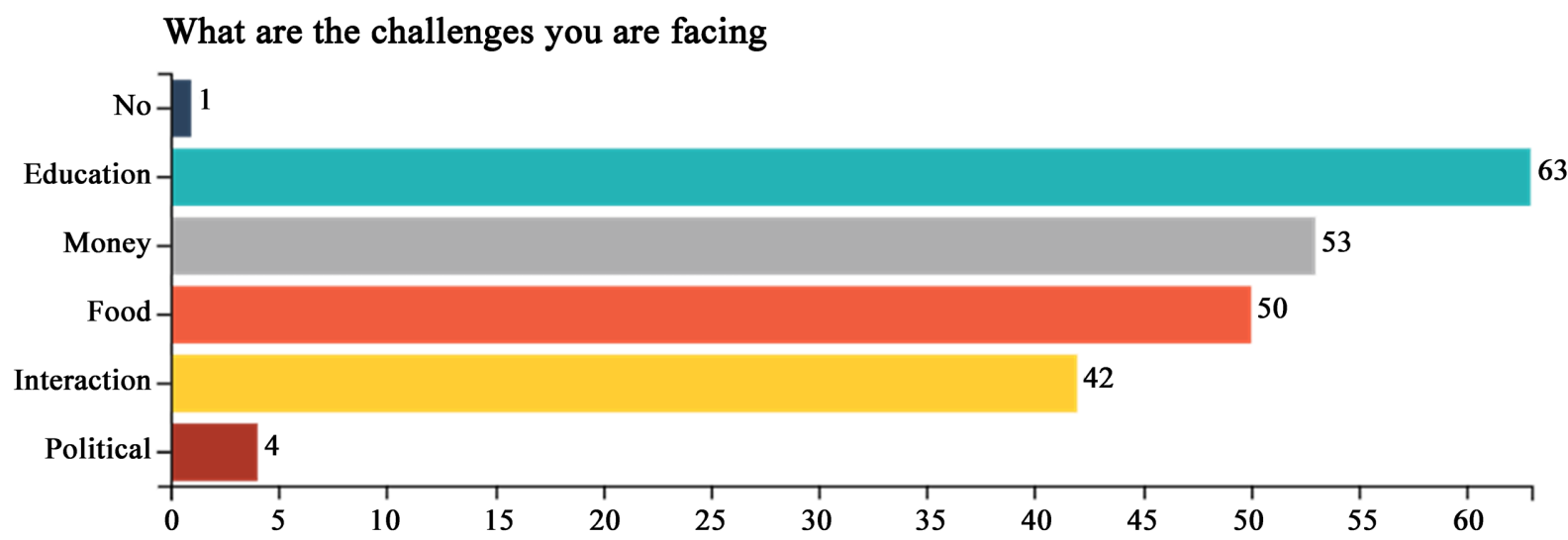

Figure 5. Challenges facing Children with disabilities.

schools, not public schools. In Chiredzi South there are no private schools, thereby excluding the children with disabilities from accessing this service. This shows that the gap between the urban and rural poor is broadening and this affects more children with disabilities who are already vulnerable. Moreso, special teachers were not offering services to students because schools were closed.

There was unavailability of income during the pandemic era because of the clamp down of the informal economy. Most parents for children with disabilities relied on informal trading which was banned during the first phase of the pandemic from March to August 2020. Some parents of children with disabilities relied on South Africa remittances that decreased significantly due to lock down measures. Cross boarder traders were heavily affected since boarders were closed for individuals. This even impacted the number of meals that children were eating. There was a significant number of about $70 \%$ of children who were eating only two meals and less because the parents could no longer afford three to four meals a day. Lack of adequate food has big repercussions on children's diet, growth level and ability to cope with their disabilities. This can lead to malnutrition, wasting and deterioration of their mental functionality leading to a dys- 
functional generation of children with disabilities. It should be a cause of concern to parents and nation at large, where the future of children is destroyed if the issues are not addressed swiftly. Lack of income has a ripple effect on affordability by parents to pay school fees. The data showed that only 17 children were enrolled at school because the parents could not afford to pay school fees.

In addition, most children with disabilities highlighted that they did not manage to interact with other students or children since they were homebound. They felt lonely because their parents spent most of the time trying to make ends meet. Some felt stigmatised by their siblings and close relatives because they rely on them for help. Children with multiple disabilities were the most affected as they cannot do most of the things on their own, some highlighted that they need help to go to the toilet, eat and sit properly. Being home-bound without interacting with other children destroyed their interaction skills and further isolated them.

Furthermore, there were some concerns that were raised by carers of children with disabilities who highlighted that some local leaders were making it harder for parents with children with disabilities to access humanitarian aid from NGOs because of political reasons. Therefore, fewer children indicated that they are affected politically, because their parents are victims of political intolerance and they were also painted with the same brush. It is worrisome to learn that political interference has affected the livelihoods of some children with disabilities by denying them access to food aid.

Moreso, school closure due to COVID-19 has negatively affected mentally challenged children who cannot concentrate on schoolwork without a specialised teacher. Most of these children could not sit down and follow radio lessons on their own. Children with hearing disabilities could not attend radio lessons, they wanted their parents to be with them to do sign language. This means that some students failed to get some specialised care for them to be able to learn from home. Some students at secondary level did not have laptops or smartphones for them to conduct researches online and the network is also a big challenge as mentioned earlier. Also, the parents could not afford to buy the laptops for the research. Therefore, these students were left behind during the closure of schools period.

Compliance with COVID-19 measures was another challenge faced by children with disabilities. Firstly, children with breathing challenges indicated that it was difficult for them to mask up while going to health centres to access their medication. These children were prone to contract COVID-19 since they could not mask up. Secondly, some children who rely on lip-reading could not do it as most people were masking up. This posed communication challenges for them. Thirdly, washing hands with running water was a challenge since water was very scarce during data collection period and people in rural communities rely on well water not tap or running water. Fourthly, access to soap was a privilege to some children as the parents could not afford to have soap for prolonged handwashing. Fifthly, social distance was difficult since children with disabilities need 
assistance from others in their day-to-day life. They rely on help from their carers and other people so social distancing was not ideal for them. One key informant indicated that "getting a wheelchair for a student is a mammoth task for parents, they can't afford them and our poor dirty roads are also not ideal for wheelchairs so they easily break down". He went on to say, "it means these children rely on their parents or older siblings to lift them up to go about their businesses that includes going to the toilet". Therefore, ordinary wheelchairs without big and durable tyres are not ideal in Chiredzi for children with disabilities to be fully mobile.

In addition, some children with disabilities indicated that they were not accessing medication they need for everyday living since they have chronic ailments. These children could not travel to hospitals in Chiredzi and beyond freely since there was no public transport in the area. The government banned the movement of private transport during the first phase of COVID-19; this is how these children were affected. Figure 6 below shows that $70.7 \%$ of children did not access their medication while only $29.3 \%$ managed to access their medication (Figure 6).

Failure to access medication for children with disabilities who needed medication resulted in many health complications. Some children mentioned that the drugs they wanted were not readily available at Chiredzi public hospital; they were given prescriptions to go and buy at private pharmaceuticals. The huge amount of out-of-pocket expenses impacted children with disabilities as it became difficulty for the parents to pay transport costs and buy the drugs monthly. One parent said, "mwana vangu akutonyanya kudonha nekuti haana kutora mapiritsi ake kuChiredzi hakuna chekufambisa kuno ZUPCO haifambe” literal meaning, "my child s frequency of falling down with epiplepsy has increased because I couldn't take his tablets at Chiredzi Hospital because there is no ZUPCO transport us".

Are you able to get your medication

(Only for ones who take)

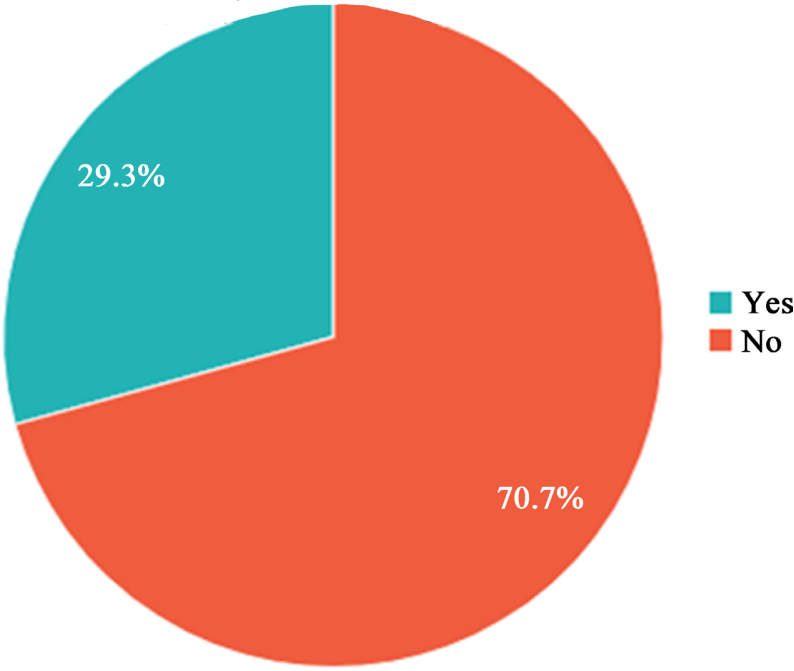

Figure 6. Access to medication. 


\subsection{Supporting Children with Disabilities during COVID-19}

In a bid to support children with disabilities most parents indicated that it was difficult for them to teach these children while schools were closed due to COVID-19 because they did not have special skills to do so. This might have a negative impact on these children since they are already behind their school curriculum. A parent said, "It will be difficult for my son to catch up on schoolwork when schools reopen because he is a slow learner who is further overburdened by school closures". It is not always the case that parents are good teachers or literate. Children of illiterate parents are further excluded and these include children with disabilities. Parents and carers of children with disabilities managed to provide minimal basic requirements as mentioned earlier.

Despite the challenges that were faced by children with disabilities they did not receive much support to address their challenges because of lockdown movement restrictions. Few respondents indicated that they were receiving minimal support from Non-Governmental Organisations and Government Social Welfare department and individuals. The humanitarian organisations were no longer operating in the area because of movement restrictions that were imposed by the government. The department of Social Welfare rarely gave social welfare packages to children with disabilities. The carers and children with disabilities were literally left to look after themselves.

\subsection{Basic and Strategic Needs of Children with Disabilities Pre, during and Post COVID-19}

Figure 7 illustrates the support required by children with disabilities.

The diagram shows that initiatives in Chiredzi should focus mostly on giving movement aids to children who have physical disabilities in the form of wheelchairs, boots and cratches. Support required by children with disabilities is enablers (wheelchairs, boots, clutches, hearing aids) but these enablers should be ideal for the dirty rough roads. The parents recommended wheel chares with bigger durable wheels, boots and clutches with thick rubbers. Some students who were supposed to go for secondary school failed to do so because of immobility as they were too heavy to be carried to school by their guardians everyday. Schools are also far away, the distance to secondary schools ranges from $10-15$ $\mathrm{km}$. Distribution of masks which are transparent on the mouth sections was

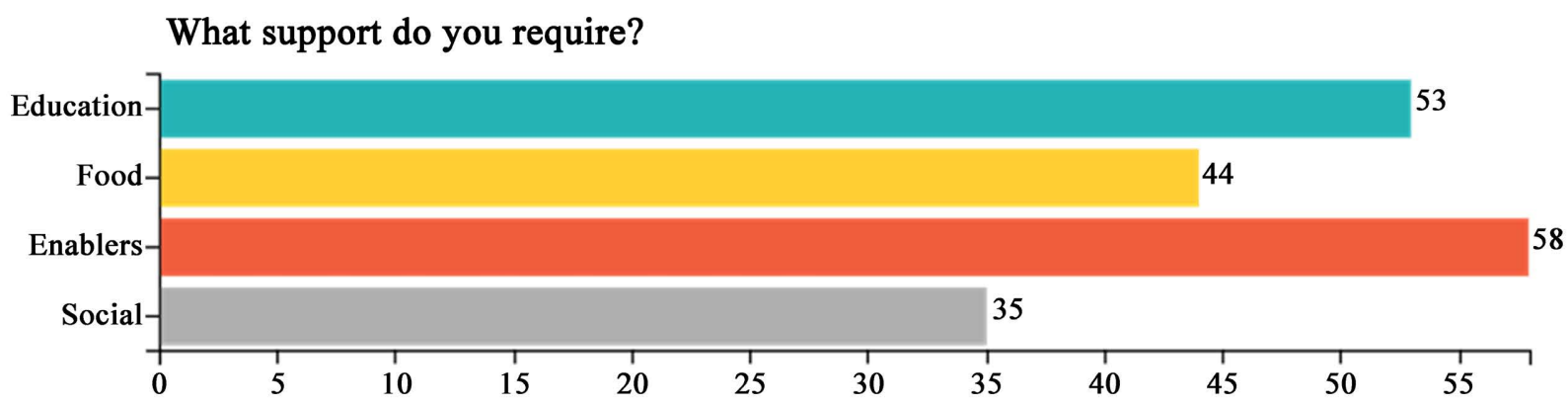

Figure 7. Support required. 
also recommended since there are some children who rely on lip-reading.

In addition, education support was the second need raised; this covers availability of textbooks, stationery, school fees and specialised teachers. With the advent of radio lessons and online researches, the parents who have radio wave signals and some network signals would like to have radios to use for lessons. Secondary school children required laptops for online research. Generally, the area requires upgrade of telecommunication infrastructure for children to access public radio lessons and conduct some online lessons. Availability of special teachers at school with proper protective equipment was another support that was required by children with disabilities even when schools are closed so that they can have a catch up with teachers. This will help children living with illiterate guidance who cannot help them with learning while at home.

Furthermore, children with disabilities required food to eat since most of them indicated that the frequency of their meals was reduced due to economic hardships and lockdown enforcement that reduced remittances from their relatives who work in South Africa. The distribution of social protection grants can be essential for children with disabilities as these can cater to their basic needs such as access to food, stationery and medicines.

The children also indicated that they would like health support especially for chronic needs ones who rely on medication. They wanted the local health centres to be provided with their chronic drugs rather than for them to travel to hospitals and buy the drugs in private pharmacies. This was becoming expensive and difficult for them to access the medication.

Additionally, progressive laws were needed for children with disabilities' needs to be advanced locally and nationally. An example that was given was to have a law that subsidises or removes school fees for children with disabilities. This will increase their chances to attend secondary school.

Lastly, children with disabilities required social support from society this includes fellowship with others, recognition and free movement. Most children felt isolated by the restriction movements, they were no longer playing with their friends and interacting with their Christian families at churches. This was further raising a sense of rejection and low self-esteem within themselves.

\section{Recommendations}

From the findings and conclusions drawn thereof, this study makes the following recommendations:

The Ministry of Primary and Secondary Education and relevant local authorities (District Rural Council, Private school owners) must ensure that special teachers are always present at the schools during the lockdowns. These authorities should also ensure availability of personal protective equipment for these teachers on duty so that children with disabilities continue learning to remain at par with other children without disability.

Policy makers, including the government of Zimbabwe and Local authorities 
should put a subsidy or exemption policy for children with disabilities to have a fair chance of attending school. We acknowledge that the new education amendment act provides for all children access to state-funded basic education although children are still paying. Policymakers should make follow up and ensure that these provisions or requirements of the legislation are implemented

The Government of Zimbabwe must make the public transport policy framework more flexible so that the framework allows other private transporters to operate in areas and communities where public transport such as ZUPCO fails to serve the people.

There can be flexibility of availability of medications that are needed by children with disabilities at their local clinics rather than to have primary care only during the pandemic season. The policymakers should ensure the availability of chronic tablets for these children to be accessed at public hospitals where the costs are subsidised.

The NGO community should also chip in by ensuring availability of humanitarian aid targeted at children with disabilities for them to have balanced diet during the economic hardship times like the pandemic.

Government should also avail social welfare packages to children with disabilities for them to access basic services such as food, menstrual packages for girls and medication. The packages help parents and guardians to reduce the burden of taking care of children with disabilities since they are already putting more effort than other parents with children who do not need special care.

\section{Conclusion}

This study concluded that children in Chiredzi, Zimbabwe, suffer from a variety of disabilities that include, but are not limited to physical, learning, mental and multiple. It is concluded that in this COVID-19 era, children living with disabilities in Chiredzi, lack access to basic needs such as education, health and food. It is also concluded that children living with disabilities are in early childhood and primary school level living in Chiredzi, have not received any meaningful support from the government and non-governmental organisations during this COVID-19 era. For example, in terms of education, the children living with disabilities need to be given textbooks, stationery and specialised teachers especially in this COVID era where all school children have to practise social distance and learn online and on radio. It is also concluded that children living with disabilities are not given free health care; their parents have to buy the medicines that they require. This has become difficult for the parents in this COVID-19 era where most of them have lost their jobs. It also concluded that children living with disabilities have endured isolation due to COVID-19 restrictions of social distance that have seen schools, playgrounds, and churches closed. This paper notes that government should prioritise children with disabilities especially the ones who live in rural areas with poor parents and guardians for them to live quality life just like any other child. There should be policies that ensure that 
children with disabilities are not left behind in development and are given a fair chance of living in the country. The gap between the rich and the poor should be closed by enforcing proper policies and public budgets that have disability lenses.

\section{Conflicts of Interest}

The authors declare no conflicts of interest regarding the publication of this paper.

\section{References}

Armitage, R., \& Nellums, L. B. (2020). The COVID-19 Response Must Be Disability Inclusive. The Lancet Public Health, 5, e257. https://doi.org/10.1016/S2468-2667(20)30076-1

Bickenbach, J. E., Chatterji, S., Badley, E. M., \& Ustün, T. B. (1999). Models of Disablement, Universalism and the International Classification of Impairments, Disabilities and Handicaps. Social Science \& Medicine (1982), 48, 1173-1187.

https://doi.org/10.1016/S0277-9536(98)00441-9

Cahapay, M. A. (2020). Ushering Children with Disabilities in the "New Normal" Post-COVID-19 Period: Collective Actions in the Philippines. Disability \& Society, 36, 145-150. https://doi.org/10.1080/09687599.2020.1829557

Charlton, J. (1998). Nothing about Us without Us: Disability, Oppression and Empowerment. University of California Press. https://doi.org/10.1525/9780520925441

Dan, B. (2020). Long-Term Impact of COVID-19 on Disabled Children. Developmental Medicine and Child Neurology, 62, 1004-1004. https://doi.org/10.1111/dmcn.14603

Gumbo, O. (2020). COVID-19 Lockdown Measures on Zimbabwean Populace. Advances in Social Sciences Research Journal, 7, 797-814. https://doi.org/10.14738/assrj.77.8728

Hartshorn, K., \& McMurry, B. (2020). Effects of the COVID-19 Pandemic on ESL Learners and TESOL Practitioners in the United States. International Journal of TESOL Studies, 2, 140-157.

Jeste, S. et al. (2020). Changes in Access to Educational and Healthcare Services for Individuals with Intellectual and Developmental Disabilities during COVID-19 Restrictions. Journal of Intellectual Disability Research, 64, 825-833.

https://doi.org/10.1111/jir.12776

Kirshner, B., Gaertner, M., \& Pozzoboni, K. (2010). Tracing Transitions: The Effect of High School Closure on Displaced Students. Educational Evaluation and Policy Analysis, 3, 407-429. https://doi.org/10.3102/0162373710376823

Mishra, A. K., \& Gupta, R. (2006). Disability Index: A Measure of Deprivation among the Disabled. Economic and Political Weekly, 41, 4026-4029.

United Nations (UN) (2020). COVID-19 Response. https://www.un.org/en/coronavirus/un-secretary-general

United Nations Children's Fund (UNICEF) (2013). The State of the World's Children UNICEF's Flagship Publication-The Most Comprehensive Analysis of Global Trends Affecting Children. https://www.unicef.org/reports/state-of-worlds-children

United Nations Children's Fund (UNICEF) (2020a). East Asia and Pacific Region COVID-19 Technical Guidance.

United Nations Children's Fund (UNICEF) (2020b). Children with Disabilities. Ensuring 
Their Inclusion in COVID-19 response Strategies and Evidence Generation. UNICEF.

United Nations Children's Fund (UNICEF) (2020c). Ensuring an Inclusive Return to School for Children with Disabilities. UNICEF.

United Nations Children's Fund (UNICEF) (2021). COVID-19 Response: Considerations for Children and Adults with Disabilities. UNICEF.

Vincent, V., \& Thomas, R. (1960). Agricultural Survey of Southern Rhodesia Part 1.

World Bank Report (2020). Disability Inclusion. https://www.worldbank.org 